\title{
Experience with the "Good" Limb Induces Aberrant Synaptic Plasticity in the Perilesion Cortex after Stroke
}

\author{
Soo Young Kim, ${ }^{1}$ Rachel P. Allred, ${ }^{2 \star}$ DeAnna L. Adkins, ${ }^{4 \star}$ Kelly A. Tennant, ${ }^{3}$ Nicole A. Donlan, ${ }^{2}$ Jeffrey A. Kleim, ${ }^{5}$ \\ and Theresa A. Jones ${ }^{2,3}$ \\ ${ }^{1}$ Department of Integrative Biology, University of California, Berkeley, Berkeley, California 94720, 2Department of Psychology and ${ }^{3}$ Institute for \\ Neuroscience, University of Texas at Austin, Austin, Texas 78712, ${ }^{4}$ Department of Neurosciences, Medical University of South Carolina, Charleston, South \\ Carolina 29425, and ${ }^{5}$ School of Biological and Health Systems Engineering, Arizona State University, Tempe, Arizona 85287
}

Following unilateral stroke, the contralateral (paretic) body side is often severely impaired, and individuals naturally learn to rely more on the nonparetic body side, which involves learning new skills with it. Such compensatory hyper-reliance on the "good" body side, however, can limit functional improvements of the paretic side. In rats, motor skill training with the nonparetic forelimb (NPT) following a unilateral infarct lessens the efficacy of rehabilitative training, and reduces neuronal activation in perilesion motor cortex. However, the underlying mechanisms remain unclear. In the present study, we investigated how forelimb movement representations and synaptic restructuring in perilesion motor cortex respond to NPT and their relationship with behavioral outcomes. Forelimb representations were diminished as a result of NPT, as revealed with intracortical microstimulation mapping. Using transmission electron microscopy and stereological analyses, we found that densities of axodendritic synapses, especially axo-spinous synapses, as well as multiple synaptic boutons were increased in the perilesion cortex by NPT. The synaptic density was negatively correlated with the functional outcome of the paretic limb, as revealed in reaching performance. Furthermore, in animals with NPT, there was dissociation between astrocytic morphological features and axo-spinous synaptic density in perilesion motor cortex, compared with controls. These findings demonstrate that skill learning with the nonparetic limb following unilateral brain damage results in aberrant synaptogenesis, potentially of transcallosal projections, and this seems to hamper the functionality of the perilesion motor cortex and the paretic forelimb.

Key words: astrocyte; forelimb behavior; learned nonuse; motor cortex; stroke recovery; synaptic plasticity

\section{Introduction}

Regenerative plasticity in the injured brain is greatly shaped by behavioral experiences and linked with functional outcomes (Allred et al., 2014). Unilateral brain damage frequently causes humans and other animals to rely heavily on the nonparetic body side and to neglect to use the paretic side, limiting functionality of the impaired side due to learned nonuse (Bury and Jones, 2002; Taub et al., 2002; Adkins et al., 2004). The intact hemisphere also can have disruptive influences on the injured one, which is linked with worsened behavioral outcome in stroke patients (Ward and Cohen, 2004; Grefkes and Fink, 2011). Skilled reach training with the nonparetic forelimb (NPT) following unilateral motor cortical lesions interferes with the behavioral benefits of subsequent rehabilitative training (RT) of the paretic forelimb in rodents

Received March 2, 2015; revised April 14, 2015; accepted May 2, 2015.

Author contributions: S.Y.K., R.P.A., D.L.A., J.A.K., and T.A.J. designed research; S.Y.K., R.P.A., D.L.A., K.A.T., N.A.D., and T.A.J. performed research; J.A.K. contributed unpublished reagents/analytic tools; S.Y.K., R.P.A., D.L.A., and T.A.J. analyzed data; S.Y.K. and T.A.J. wrote the paper.

This work is supported by National Institute of Neurological Disorders and Stroke Grant NS-056839.

*R.P.A. and D.L.A. contributed equally to this work.

The authors declare no competing financial interests.

Correspondence should be addressed to Dr. Soo Young Kim, Department of Integrative Biology, University of California, Berkeley, 430E Li Ka Shing Center, \#3370, Berkeley, CA 94720-3370. E-mail: sooykim@berkeley.edu.

DOI:10.1523/JNEUROSCI.0829-15.2015

Copyright $\odot 2015$ the authors $\quad 0270-6474 / 15 / 358604-07 \$ 15.00 / 0$
(Allred et al., 2005, 2010; Allred and Jones, 2008). The detrimental effect of NPT on paretic limb function is dependent upon transcallosal connections and contralesional cortex (Allred et al., 2010). Furthermore, training with the nonparetic limb decreases FosB $/ \Delta$ FosB expression in the perilesion cortex (Allred et al., 2008 ), an early gene accumulating in response to repeated neuronal activation (McClung et al., 2004). This is potentially problematic given that plasticity in perilesion cortex is strongly implicated in functional outcome in both animals and humans (Nudo, 2013). However, a great deal is still unknown about the neural mechanisms underlying the maladaptive effects of compensatory learning with the nonparetic limb. The present study begins to reveal these mechanisms.

We found that NPT reduced forelimb representations and increased synapses in perilesion motor cortex compared with controls, which were negatively correlated with paretic limb functional improvements. Unlike the synaptogenesis observed following RT (Hsu et al., 2007), which includes increases in functionally mature perforated synapses (Ganeshina et al., 2004a), NPT increased only multiple synaptic boutons (MSBs), potentially indicating heightened synaptic competition. Furthermore, while axo-spinous synaptic densities were strongly correlated with quantities of perisynaptic astrocytes in controls, this was not found in animals receiving NPT. Our data indicate that aberrant 

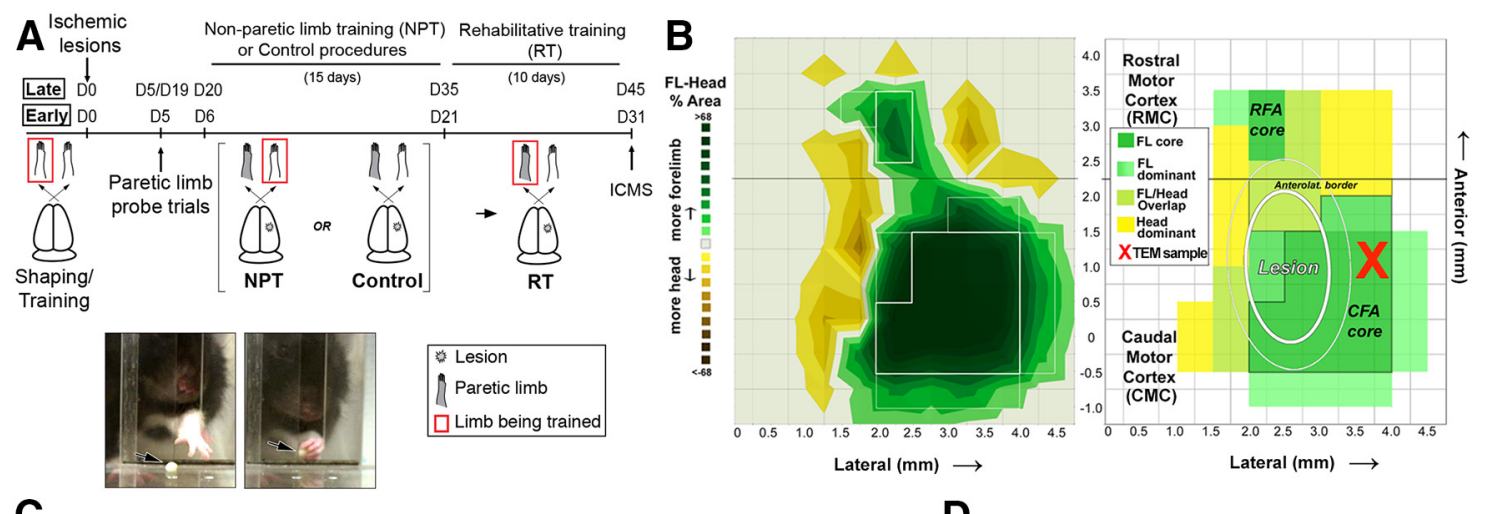

C
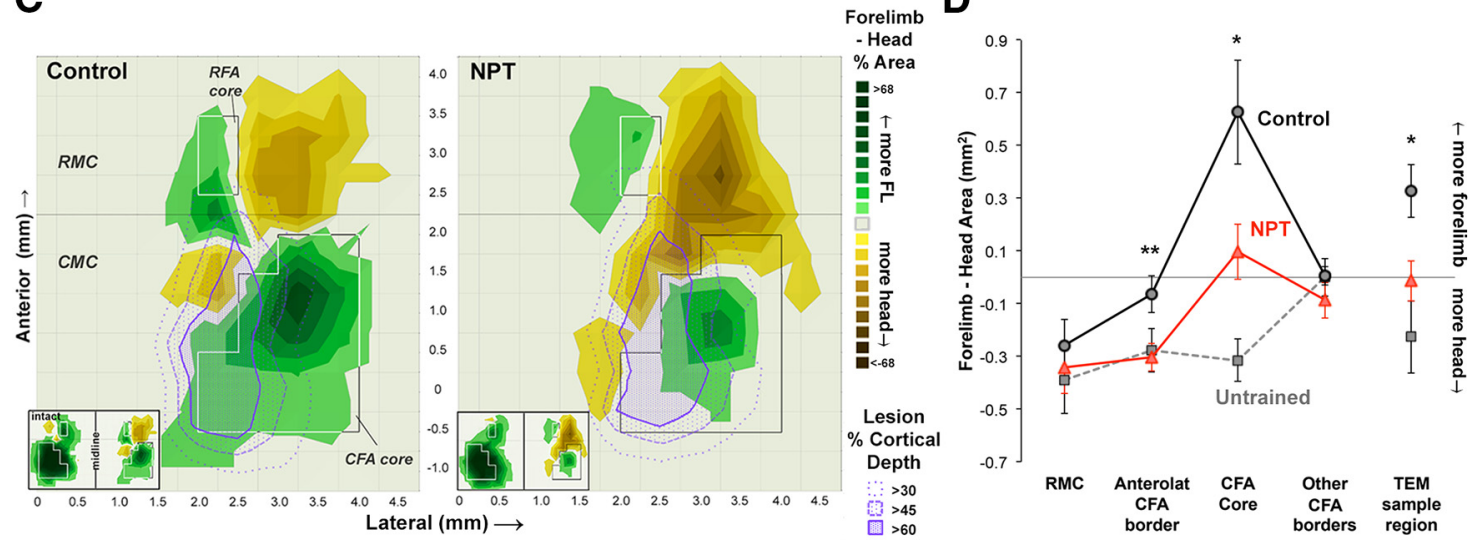

Figure 1. A, Experimental design. A rat performing the reaching task, aiming for (left) and grasping (right) the pellet (arrow). $\boldsymbol{B}$, ICMS mapping of forelimb representations in naive rats (left) used to define subregions of motor cortex (right). Transmission electron microscopy (TEM) samples were near the anterolateral border of the lesion within the CFA. RFA, Rostral forelimb area. C, In the remaining CMC, forelimb representations predominated in controls, but head representations predominated in NPT. Surface plots in $\boldsymbol{B}$ and $\boldsymbol{C}$ show the mean percentage forelimb (FL) minus percentage head area per $0.5 \times 0.5 \mathrm{~mm}$ grid square. $\boldsymbol{D}$, The CFA core and its anterolateral border showed the greatest reductions in the relative area of forelimb representations in NPT, as well as in untrained rats. A similar pattern was found in the map region closest to the TEM sample site (anteroposterior, $0.5-2.25$; mediolateral, $3.0-4.0$ ). ${ }^{*} p<0.05$, ${ }^{* *} p<0.01$, vs NPT. Anterolat, Anterolateral.

synaptic plasticity is likely to be a mechanism underlying the detrimental effects of compensatory learning with the nonparetic body side after unilateral stroke.

\section{Materials and Methods}

Animals, surgeries, and experimental design. This study used animals from a previous study (Allred et al., 2009). The prior study examined the effects of learning with the nonparetic forelimb a skilled reaching task, which before the stroke had been performed proficiently with the paretic limb (Fig. 1A). This reduced improvements in the paretic limb during subsequent RT on the same task. Briefly, 35 adult (5-month-old), male Long-Evans Hooded rats (Harlan Laboratories) were used. Lesions were induced by pial application of endothelin-1, a vasoconstrictive peptide, to partially damage the caudal forelimb area (CFA). Groups were matched for lesion-induced reaching deficits as measured $5 \mathrm{~d}$ postlesion. Animals thereafter underwent NPT (60 trials/d for $5 \mathrm{~d}$, and 120 trials/d for $10 \mathrm{~d}$ ) or control procedures, followed by RT with the paretic limb (30 trials/d for $5 \mathrm{~d}$, and 60 trials/d for an additional $5 \mathrm{~d}$ ). The $10 \mathrm{~d}$ RT period was chosen to prevent intense paretic limb training from masking NPT effects. NPT began either 6 or $20 \mathrm{~d}$ postlesion, such that there were the following four groups: Control_Early $(n=7)$, NPT_Early $(n=7)$, Control_Late $(n=8)$, and NPT_Late $(n=9)$. Training was on the singlepellet retrieval task, as described previously (Allred et al., 2010). In the control procedure, animals were placed in the reaching chamber for the same time period with food pellets on the floor. Reaching performance of the paretic limb was quantified as the percentage successful retrievals/ reach attempt. For intracortical microstimulation (ICMS), an additional 18 maps from naive rats were used as reference maps, and a small subset received no training control procedures throughout the study period (Untrained, $n=4$ ) to aid interpretations of the RT effects. All animal use was in accordance with a protocol approved by the Animal Care and Use Committee of the University of Texas at Austin. Experimenters were blind to conditions during ICMS and electron microscopy data collection.

Intracortical microstimulation mapping. At the end of RT, rats underwent standard ICMS procedures to reveal the organization of the remaining movement representations in injured motor cortex, as previously described (Boychuk et al., 2011; Tennant et al., 2011). Briefly, under superficial ketamine/xylazine anesthesia, $350 \mathrm{~Hz}$ trains of cathodal pulses $(13 \times 200 \mu \mathrm{s})$ were delivered via microelectrodes in layer $\mathrm{V}$. Movements elicited at the lowest thresholds ( $60 \mu \mathrm{A}$ maximum) defined movement representations. Remaining forelimb, as well as jaw and neck, representations of caudal motor cortex (CMC; primary motor) and rostral motor cortex (RMC; premotor/supplementary motor) were mapped at $470 \times 470 \mu \mathrm{m}$ increments in their entirety. There were no group differences in proportions of proximal versus distal forelimb, or jaw versus neck, representations, and these were combined for analyses of forelimb and head representations, respectively. Maps were analyzed with respect to motor map subdivisions defined in naive animals (Fig. $1 B)$. Alignment with these subdivisions was verified by histological measures of cytoarchitectural landmark positions in injured cortex and by comparison with less detailed maps of contralesional cortex that were generated after the perilesion maps. Representations were analyzed as relative areas (forelimb minus head) or proportions of total responsive area.

Histology. Immediately after ICMS mapping, microinjections of DiI into anterior, posterior, and lateral borders of the CFA were made to guide sample dissections. Rats were then transcardially perfused with 0.1 M phosphate buffer (PB) with heparin sodium $(0.05 \mathrm{~g} / \mathrm{L})$ followed by $2 \%$ paraformaldehyde and 2.5\% glutaraldehyde in PB. Samples between 1.2 
A

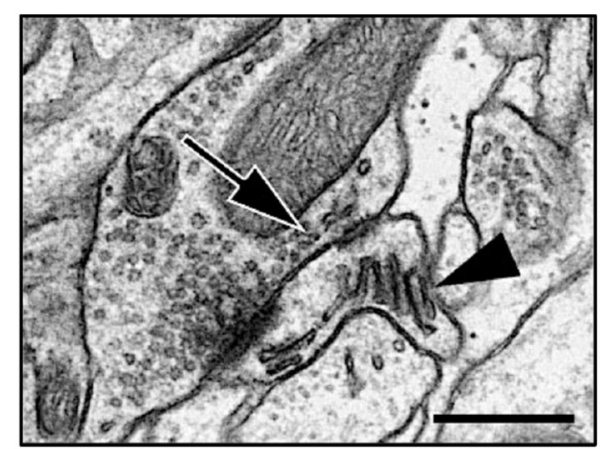

B

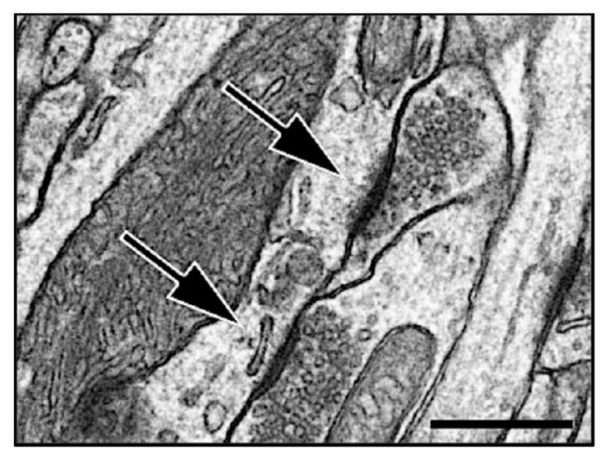

C

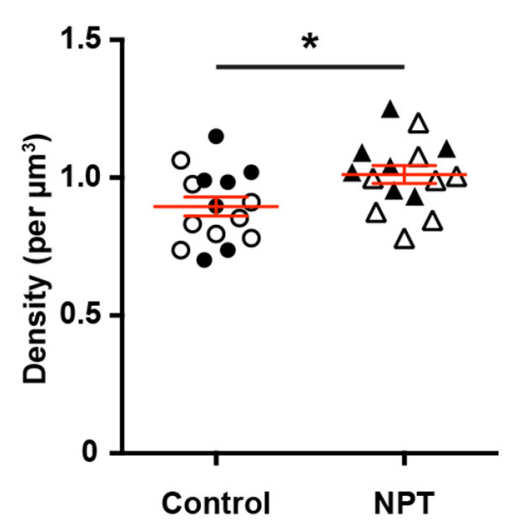

D

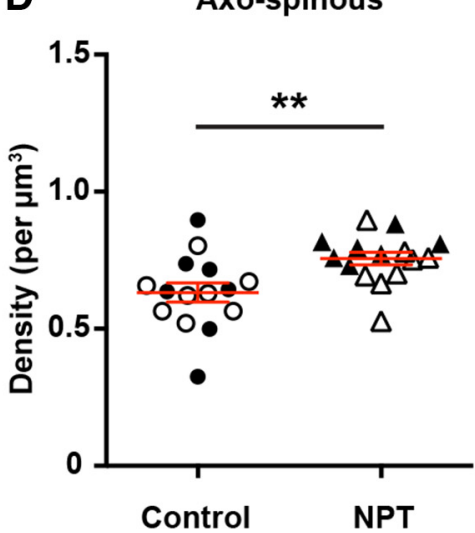

\section{Axo-shaft}

$\bullet \wedge$ Early $\circ \Delta$ Late

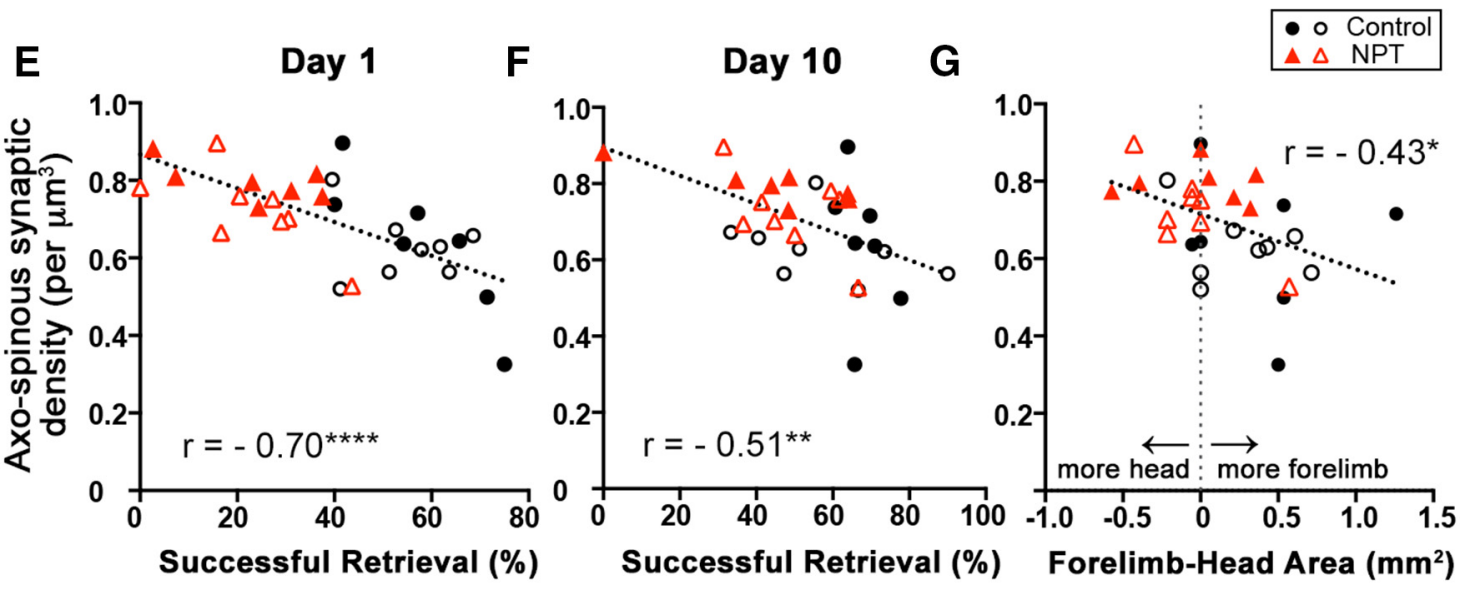

Figure 2. NPT induces synaptogenesis in peri-infarct motor cortex. $\boldsymbol{A}, \boldsymbol{B}$, Representative micrographs. Arrows indicate axo-spinous $(\boldsymbol{A})$ and axo-shaft $(\boldsymbol{B})$ synapses . The arrowhead points to a spine apparatus $(\boldsymbol{A})$. Scale bar, $500 \mathrm{~nm}$. C, NPT increased axodendritic synaptic densities in layer $V$ of perilesion motor cortex. $\boldsymbol{D}$, While there was no difference in axo-shaft synapses between groups, axo-spinous synapses were significantly increased by NPT. $\boldsymbol{E}-\boldsymbol{G}$, Axo-spinous synaptic density was negatively correlated with the reaching performance of the paretic limb on Day $1(\boldsymbol{E})$ and Day 10 $(\boldsymbol{F})$, and with relative area of forelimb representations in the sampled region $(\boldsymbol{G}) .{ }^{*} p<0.05,{ }^{* *} p<0.01,{ }^{* * * *} p<0.0001$.

and $1.6 \mathrm{~mm}$ anterior to bregma, lateral to the lesions, and within lateral agranular cortex were chosen because this was the most common intact CMC region where forelimb movements were evoked (Fig. 1B). In a subset ( $n=3$ controls, $n=5$ NPT rats), this sample location did not include forelimb representations as revealed in ICMS, but there was no difference in anatomical variables compared with those that did. Samples were osmicated, dehydrated, resin embedded, and sectioned as described previously (Kim and Jones, 2010). Serial coronal semithin sections (800 $\mathrm{nm}$ ) stained with Toluidine Blue were used to guide sample block trimming to layer V. Serial ultrathin $(70 \mathrm{~nm})$ sections were mounted on Formvar-coated slotted grids and stained with lead citrate. Samples from one animal (NPT_Late group) were omitted due to histological errors.

Transmission electron microscopy and stereological quantification. Axodendritic (spine and shaft) synaptic density was estimated using the physical disector method (Sterio, 1984). Four sets of four serially posi- tioned micrographs per brain were obtained using an FEI Tecnai transmission electron microscope with an Advanced Microscopy Techniques Advantage HR 1 megapixel digital camera (16,500× image capture magnification, digitally viewed at $50,000 \times$ ). All images were coded to obscure experimental conditions. The criteria to identify synapses and astrocytic processes were the same as described previously (Kim and Jones, 2010). Synaptic density was calculated as the sum of synapses counted per brain divided by sample volume $\left(138.3 \mu \mathrm{m}^{3}\right)$, the product of the sample frame area $\left(82.3 \mu \mathrm{m}^{2}\right)$, section thickness $(70 \mathrm{~nm})$, and number of disector pairs (24 pairs). Synapse subtypes were classified, including the following: (1) perforated synapses possessing discontinuous postsynaptic densities; (2) MSBs forming synapses with more than one distinct dendritic element (spine and/or shaft); (3) multiple synaptic spines (MSSs) forming synapses with more than one axonal bouton; and (4) axo-spinous, (5) axo-shaft, and (6) symmetric synapses. The software program RECONSTRUCT (Fiala, 
A

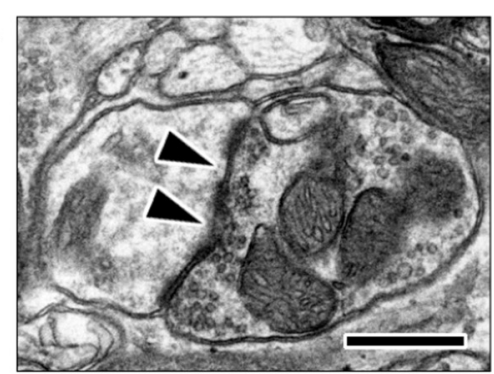

B

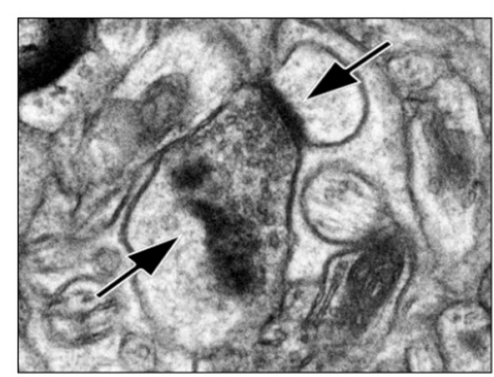

C

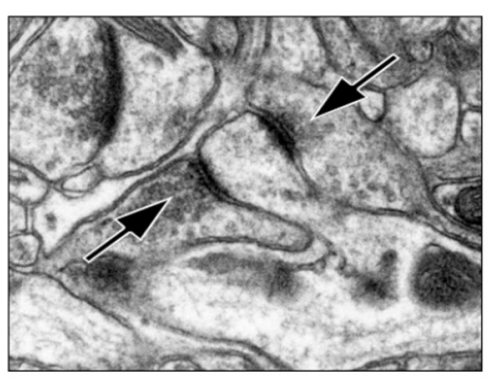

D

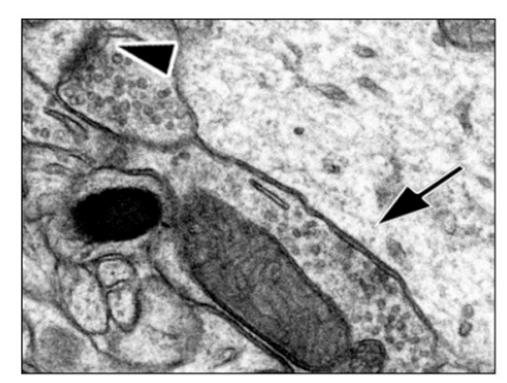

$E$

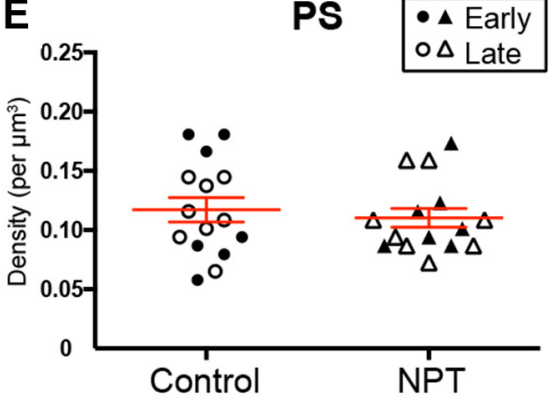

$\mathbf{F}$

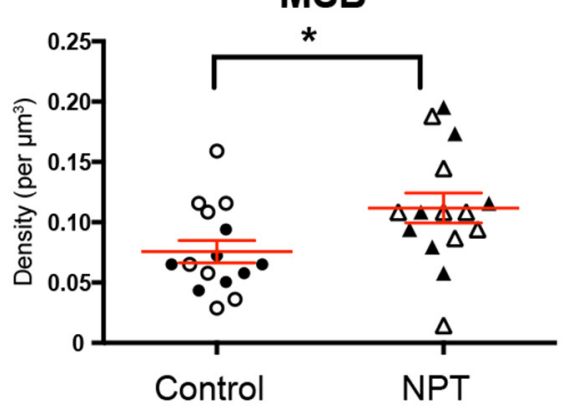

G

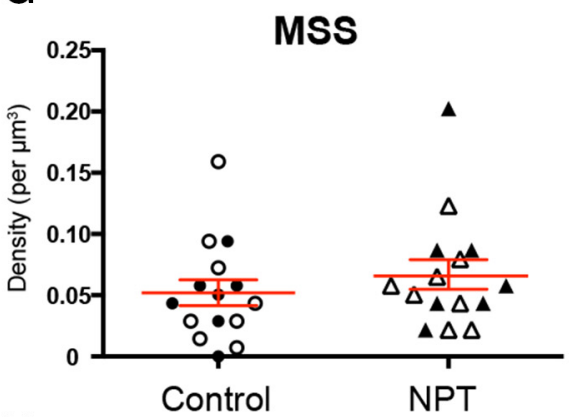

H

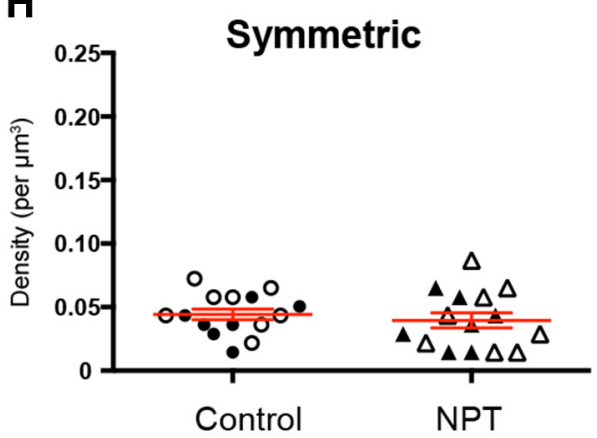

Figure 3. NPT increases MSBs in layer V of the perilesion cortex. $A-D$, Examples of synaptic subtypes. Scale bar, $500 \mathrm{~nm}$. $\boldsymbol{A}$, Perforated synapse (PS) with discontinuities (arrowheads) in the postsynaptic density. $\boldsymbol{B}$, MSBs forming synapses with two spines. Arrows point to postsynaptic densities. C, MSSs forming synapses with two boutons. D, Axon-containing flat vesicles forming a synapse, presumeably inhibitory, with a symmetric postsynaptic density (arrow), which is distinct from the round vesicles in an asymmetric synapse (arrowhead). $\boldsymbol{E}-\boldsymbol{H}, 0$ nly MSB synapses were significantly increased in NPT $(\boldsymbol{F})$. ${ }^{*} p<0.05$.

2005) was used to trace astrocytic processes and estimate their volume $\left(V_{\text {astro }}\right)$ and surface area $\left(S a_{\text {astro }}\right)$. Volume fraction $\left(V v=V_{\text {astro }} /\right.$ total sample volume $)$ and surface area/volume ratio $\left(S a_{\text {astro }} / V_{\text {astro }}\right)$ were then calculated.

Statistical analyses. Data were analyzed using Prism 6 (GraphPad). Because there were no effects of the onset of training on anatomical measures, early and late groups were combined to simplify the presentation. Data were analyzed with unbiased Student's $t$ tests and Pearson correlations with two-tailed significance tests. Effects were considered significant at $p<0.05$. Descriptive results are presented as the mean $\pm \mathrm{SE}$.

\section{Results}

Learning with the nonparetic limb diminishes forelimb, at the expense of head, representations in perilesion motor cortex

Previously, NPT beginning either 6 or $20 \mathrm{~d}$ postlesion was found to interfere with spontaneous recovery of the paretic limb and its functional improvements over $10 \mathrm{~d}$ of subsequent RT (Allred et al., 2009). In the present study, we found that NPT diminished the representation of the paretic forelimb in perilesion cortex as revealed with ICMS (Fig. 1C,D). Overall, NPT groups had more head representation area in CMC $\left(0.814 \pm 0.120 \mathrm{~mm}^{2}\right)$ than forelimb representation area in CMC $(0.455 \pm 0.110)$, whereas controls had more forelimb representation area in CMC $(0.945 \pm 0.271)$ than head representation area in CMC $(0.358 \pm 0.052)$. The relative area of forelimb representations was significantly reduced in NPT rats versus controls in CMC $\left(t_{(29)}=3.20\right.$, $p=0.003)$, but not in $\operatorname{RMC}\left(t_{(28)}=0.60\right)$. There were no significant group differences in lesion volume (NPT rats, $10.02 \pm$ $1.36 \mathrm{~mm}^{3}$; controls, $10.67 \pm 0.88 \mathrm{~mm}^{3}$ ), total CMC map area (NPT rats, $1.90 \pm$ $0.24 \mathrm{~mm}^{2}$; controls, $1.80 \pm 0.40 \mathrm{~mm}^{2}$ ), or movement thresholds (NPT rats, $41.7 \pm$ $1.4 \mu \mathrm{A}$; controls, $44.1 \pm 1.6 \mu \mathrm{A})$, which were similar for head $(44.3 \pm 1.8 \mu \mathrm{A})$ and forelimb $(42.2 \pm 1.3 \mu \mathrm{A})$ representations.

Because the CFA core region was mapped exhaustively, we also analyzed other movement representations here, which were largely vibrissae representations. Considering animals with any remaining representations in CFA core $(n=$ 14 NPT rats; $n=13$ controls), forelimb representations made up the majority of the remaining map of controls $(75.0 \pm 8.12 \%$ vs $32.1 \pm 9.3 \%$ in NPT rats; $t_{(25)}=3.46, p=$ $0.002)$. In contrast, jaw/neck and vibrissae representations together made up the majority in NPT rats $(64.9 \pm 9.8 \%$ vs $23.8 \pm$ $7.8 \%$ in controls; $\left.t_{(25)}=3.25, p=0.003\right)$. In rats without training during either NPT or RT periods (Untrained, $n=4$ ), head representations also dominated the CFA core map $(83.3 \pm 14.4 \% \mathrm{jaw} /$ neck/vibrissae $)$.

This suggests that RT maintained and/or resurrected forelimb movement representations in the remaining CFA of controls and that NPT countered this effect.

Paretic forelimb performance as averaged over test days was positively correlated with the proportion of forelimb representations in the CFA core $(r=0.49, p=0.011)$ and their relative area in CMC overall $(r=0.39, p=0.032)$. Together, these results suggest that the capacity of RT to promote functionally 
relevant motor map organization in perilesion cortex is disrupted by NPT.

Learning with the nonparetic limb increases synaptic density in perilesion motor cortex, and this is negatively correlated with paretic limb function In the same region showing diminished forelimb representations, axodendritic synaptic density was found to be significantly higher in NPT groups than in controls $\left(t_{(28)}=2.45, p=0.02\right.$; Fig. $\left.2 C\right)$. The density of axo-spinous synapses was increased in NPT groups compared with controls $\left(t_{(28)}=2.97, p=0.006\right.$; Fig. $\left.2 D\right)$, while axo-shaft synaptic densities did not change $\left(t_{(28)}=0.32, p=0.75\right)$. Thus, the newly formed synapses were mostly axospinous. There were no group differences in neuronal densities (data not shown).

To determine whether synapse density in perilesion cortex was associated with functional outcome, correlations between synaptic density and reaching performance were examined. There was a negative correlation between densities of axodendritic synapses and paretic limb reaching performance on the first day of its testing after NPT $(r=-0.57, p=$ $0.001)$. There was a stronger inverse relationship between paretic limb reaching performance and the density of axospinous synapses (Fig. 2E). The inverse relationship between reaching performance and synaptic densities remained on the last day of RT (Day10; with axodendritic synapses, $r=-0.46, p=0.01$; with axospinous synapses; Fig. $2 F$ ). Correlations within individual groups were also examined. Axo-spinous synaptic densities of both groups had an inverse relationship with reaching performance on the first day of paretic limb testing $(r=-0.65, p<$ 0.01 for controls; $r=-0.56, p<0.05$ for NPT rats). While such an inverse relationship between synapses and reaching performance still existed in NPT on the last day of RT (Day10; $r=-0.56, p<0.05$ ), there was no significance correlation in controls $(r=-0.23, p>0.05)$. Similarly, there was an inverse correlation between axo-spinous synapses and the relative area of forelimb representations in the sampled region (Fig. $2 G$ ). Thus, the induction by NPT of new axo-spinous synapses in the perilesion cortex is associated with neither the functional integrity of surviving forelimb cortex nor improvements in the paretic limb.

NPT induces the formation of multiple synaptic boutons in perilesion motor cortex

To characterize which synapse subtypes were formed in the perilesion cortex following NPT, densities of four subtypes were examined (Fig. 3). While there were no group differences in other types of

A

B

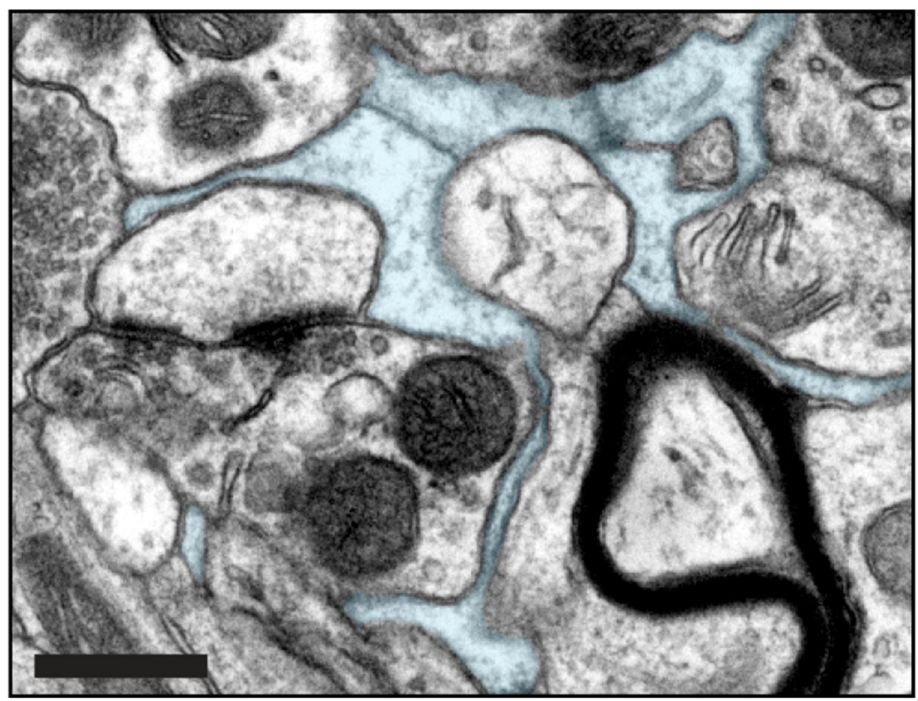

Control
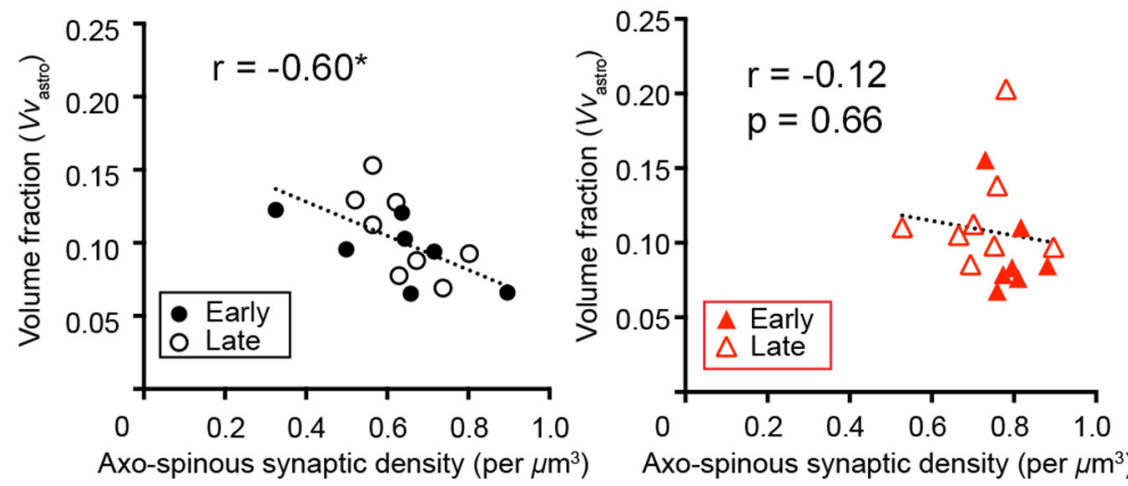

Axo-spinous synaptic density (per $\left.\mu \mathrm{m}^{3}\right)$
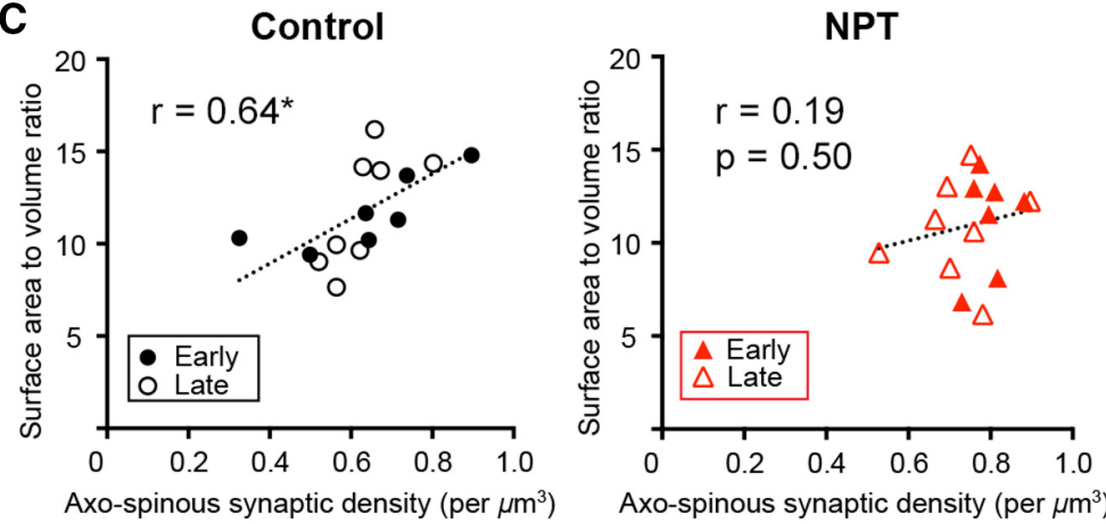

Figure 4. There was no association between astrocytic morphological features and axo-spinous synapse numbers in the perilesion cortex following NPT. A, Astrocytic processes (blue) wrap around synapses. Scale bar, $500 \mathrm{~nm}$. B, C, Axo-spinous synaptic density in controls, but not NPT, was significantly correlated with both astrocyte volume fraction $(\boldsymbol{B})$ and surface area/volume ratio of astrocytic processes $(\boldsymbol{C}){ }^{*} p<0.05$.

synapses ( $p$ values $>0.05$ ), NPT increased the density of MSBs in the perilesion cortex $\left(t_{(28)}=2.33, p=0.027\right.$; Fig. $\left.3 F\right)$. The density of single synaptic boutons (non-MSBs) was similar across the group (controls, $0.820 \pm 0.031$; NPT rats, $0.900 \pm 0.034 ; p=0.091$ ). Thus, increases in synaptic density in perilesion cortex following NPT primarily resulted from the addition of MSBs.

Coordinated plasticity between astrocytes and synapses was not apparent following NPT

Perisynaptic astrocytic processes rapidly alter their morphology and change proximity with synapses in coordination with struc- 
tural changes in spines (Haber et al., 2006). We examined whether there was a tight association between astrocytic morphological features and synaptic densities in perilesion cortex. While axo-spinous synaptic densities in controls were significantly correlated with both astrocytic volume fraction and surface area/ volume ratio ( $p$ values $<0.05$ ), there was no such significant association following NPT (Fig. 4). NPT did not alter astrocytic volume fraction or surface area/volume ratio ( $p$ values $>0.05$ ).

\section{Discussion}

Many previous studies (Johansson, 2000; Murphy and Corbett, 2009; Nudo, 2013) have investigated how behavioral experiences can promote functionally beneficial brain plasticity after injury. However, unilateral brain damage often leaves the use of paretic limbs neglected, a condition called "learned nonuse" (Taub et al., 2002), and increases reliance on the nonparetic side. We found that NPT had a major influence on the organization of perilesion motor cortex. After $10 \mathrm{~d}$ of RT, the remaining motor maps of controls had expanded representations of the paretic forelimb, linked with better behavioral function, while the maps of those that underwent NPT before RT were dominated by head representations. Movement representations are maintained by activity-dependent competition between bordering representations (Nudo, 2013). Thus, NPT appears to diminish effective competition between surviving forelimb and surrounding head representations. Surprisingly, this effect was linked with increased axo-spinous synapses in perilesion cortex. These synapses had an inverse relationship with functional improvements of the paretic limb and its representation in perilesion cortex. A specific synapse subtype, synapses formed by MSBs, was the most prominent contributor to NPT-induced increases in synapse number. While there was a tight association between astrocytic morphological features and synapse numbers in controls, this was not found after NPT. Therefore, these findings indicate that NPT induces aberrant synaptic plasticity that is neither associated with paretic limb improvements nor is accompanied by coordinated astrocytic changes.

The detrimental effect of skill learning with the nonparetic limb is dependent upon both transcallosal connections and contralesional cortex (Allred et al., 2010). A higher density of synapses potentially reflects a greater quantity of transcallosal connections from the contralesional cortex. Most transcallosal cortical projections form direct excitatory synapses onto pyramidal neurons and GABAergic interneurons (Kawaguchi, 1992; Karayannis et al., 2007). Furthermore, either bilateral training (Allred and Jones, 2008) or home-cage bimanual experience (Kerr et al., 2013) can attenuate deleterious NPT effects, suggesting substantial involvement of interhemispheric competition in these effects.

Whatever the afferent source, the promotion of synaptogenesis by NPT can be assumed to alter connectivity in perilesion cortex, and this may compete with the capacity of RT to do so. The finding that NPT increases MSBs is consistent with greater synaptic competition. In rat cerebellum, excitatory synapses adjacent to MSBs are smaller, suggesting a compensatory weakening of synapses adjacent to MSBs (Lee et al., 2013). Thus, the proliferation of MSBs after NPT may reflect the strengthening of synapses activated during NPT, which then dampened the efficacy of the paretic limb in driving activity-dependent plasticity of neighboring synapses, interfering with establishment of more functionally relevant circuits.

The finding that animals with NPT had a greater overall density of axodendritic synapses, but not perforated synapses, a sub- type having abundant AMPA receptors and greater synaptic efficacy (Ganeshina et al., 2004a, b), also implies altered synaptic maturation. In contrast, RT increases the density of perforated synapses, which is tightly associated with functional improvements (Hsu et al., 2007). Further study is needed to investigate whether receptor distributions and synaptic activity are affected by NPT.

Experience-dependent plasticity involves rapid structural changes in synapses, particularly dendritic spines (Xu et al., 2009). Astrocytes are highly motile in accordance with dendritic spine structural change (Haber et al., 2006). The coordinated structural plasticity between astrocytes and spines occurs prominently when synapses are functionally active (Perez-Alvarez et al., 2014). Astrocytes actively eliminate weak synapses when overall neuronal activity is heightened (Chung et al., 2013) and refine synaptic connectivity via synaptic competition (Risher et al., 2014) in cortex. The tight association between astrocytic morphological features and axo-spinous synapses in controls may reflect the coordination of astrocytic changes with that of synapses activated by paretic limb training during RT. Furthermore, synapses with more morphologically mature features have more stable contacts with astrocytes (Haber et al., 2006), yet have a longer astrocyte-free perimeter around synaptic cleft, presumably increasing synaptic cross talk (Witcher et al., 2007). The latter may partly explain the inverse correlation between astrocytic volume fraction and synapse number in controls. In contrast, NPT-induced synaptogenesis may mostly involve synapses that are weakly activated by RT and hence are more dissociated with astrocytic structure. In any event, the finding that the controls had better functional improvements and fewer synapses, but with stronger relationships with perisynaptic astrocytic structure and forelimb motor maps, is consistent with more effective activity-dependent remodeling of perilesion cortex compared with NPT. Further study of how NPT affects glia-neuron interactions is warranted by these results.

The present study demonstrates that maladaptive training with the nonparetic limb disrupts functionally relevant reorganization of perilesion motor cortex. The unexpected finding of higher densities of axo-spinous synapses and MSBs within the same region strongly implicates aberrant synaptic plasticity as a mechanism underlying the disruption of cortical reorganization and paretic limb functional improvements. We suggest that the increase in synapses, which may arise from transcallosal projections, confiscates circuitry in peri-infarct cortex, limiting its potential for later rewiring to mediate better paretic limb function.

\section{References}

Adkins DL, Voorhies AC, Jones TA (2004) Behavioral and neuroplastic effects of focal endothelin-1 induced sensorimotor cortex lesions. Neuroscience 128:473-486. CrossRef Medline

Allred RP, Jones TA (2008) Maladaptive effects of learning with the lessaffected forelimb after focal cortical infarcts in rats. Exp Neurol 210:172181. CrossRef Medline

Allred RP, Maldonado MA, Hsu And JE, Jones TA (2005) Training the "lessaffected" forelimb after unilateral cortical infarcts interferes with functional recovery of the impaired forelimb in rats. Restor Neurol Neurosci 23:297-302. Medline

Allred RP, Adkins DL, Kim SY, Cappellini CH, Tennant KA, Donlan NA, McPartlin A, Kleim JA, Jones TA (2009) Disruption of perilesion motor maps by learning with the ipsilesional limb after unilateral sensorimotor cortex lesions. Soc Neurosci Abstr 35:363.12.

Allred RP, Cappellini CH, Jones TA (2010) The "good" limb makes the "bad" limb worse: experience-dependent interhemispheric disruption of functional outcome after cortical infarcts in rats. Behav Neurosci 124: 124-132. CrossRef Medline 
Allred RP, Kim SY, Jones TA (2014) Use it and/or lose it-experience effects on brain remodeling across time after stroke. Front Hum Neurosci 8:379. CrossRef Medline

Boychuk JA, Adkins DL, Kleim JA (2011) Distributed versus focal cortical stimulation to enhance motor function and motor map plasticity in a rodent model of ischemia. Neurorehabil Neural Repair 25:88-97. CrossRef Medline

Bury SD, Jones TA (2002) Unilateral sensorimotor cortex lesions in adult rats facilitate motor skill learning with the "unaffected" forelimb and training-induced dendritic structural plasticity in the motor cortex. J Neurosci 22:8597-8606. Medline

Chung WS, Clarke LE, Wang GX, Stafford BK, Sher A, Chakraborty C, Joung J, Foo LC, Thompson A, Chen C, Smith SJ, Barres BA (2013) Astrocytes mediate synapse elimination through MEGF10 and MERTK pathways. Nature 504:394-400. CrossRef Medline

Fiala JC (2005) Reconstruct: a free editor for serial section microscopy. J Microsc 218:52-61. CrossRef Medline

Ganeshina O, Berry RW, Petralia RS, Nicholson DA, Geinisman Y (2004a) Synapses with a segmented, completely partitioned postsynaptic density express more AMPA receptors than other axospinous synaptic junctions. Neuroscience 125:615-623. CrossRef Medline

Ganeshina O, Berry RW, Petralia RS, Nicholson DA, Geinisman Y (2004b) Differences in the expression of AMPA and NMDA receptors between axospinous perforated and nonperforated synapses are related to the configuration and size of postsynaptic densities. J Comp Neurol 468:86-95. CrossRef Medline

Grefkes C, Fink GR (2011) Reorganization of cerebral networks after stroke: new insights from neuroimaging with connectivity approaches. Brain 134:1264-1276. CrossRef Medline

Haber M, Zhou L, Murai KK (2006) Cooperative astrocyte and dendritic spine dynamics at hippocampal excitatory synapses. J Neurosci 26:88818891. CrossRef Medline

Hsu JE, Donlan NA, Kleim JA, Jones TA (2007) Protein synthesis inhibition in the perilesion cortex disrupts functional recovery and structural plasticity induced by rehabilitative training after unilateral cortical infarct in rats. Soc Neurosci Abstr 33:899.15.

Johansson BB (2000) Brain plasticity and stroke rehabilitation. Stroke 31: 223-230. CrossRef Medline

Karayannis T, Huerta-Ocampo I, Capogna M (2007) GABAergic and pyramidal neurons of deep cortical layers directly receive and differently integrate callosal input. Cereb Cortex 17:1213-1226. CrossRef Medline

Kawaguchi Y (1992) Receptor subtypes involved in callosally-induced post- synaptic potentials in rat frontal agranular cortex in vitro. Exp Brain Res 88:33-40. CrossRef Medline

Kerr AL, Wolke ML, Bell JA, Jones TA (2013) Post-stroke protection from maladaptive effects of learning with the non-paretic forelimb by bimanual home cage experience in C57BL/6 mice. Behav Brain Res 252:180-187. CrossRef Medline

Kim SY, Jones TA (2010) Lesion size-dependent synaptic and astrocytic responses in cortex contralateral to infarcts in middle-aged rats. Synapse 64:659-671. CrossRef Medline

Lee KJ, Park IS, Kim H, Greenough WT, Pak DT, Rhyu IJ (2013) Motor skill training induces coordinated strengthening and weakening between neighboring synapses. J Neurosci 33:9794-9799. CrossRef Medline

McClung CA, Ulery PG, Perrotti LI, Zachariou V, Berton O, Nestler EJ (2004) DeltaFosB: a molecular switch for long-term adaptation in the brain. Brain Res Mol Brain Res 132:146-154. CrossRef Medline

Murphy TH, Corbett D (2009) Plasticity during stroke recovery: from synapse to behaviour. Nat Rev Neurosci 10:861-872. CrossRef Medline

Nudo RJ (2013) Recovery after brain injury: mechanisms and principles. Front Hum Neurosci 7:887. CrossRef Medline

Perez-Alvarez A, Navarrete M, Covelo A, Martin ED, Araque A (2014) Structural and functional plasticity of astrocyte processes and dendritic spine interactions. J Neurosci 34:12738-12744. CrossRef Medline

Risher WC, Patel S, Kim IH, Uezu A, Bhagat S, Wilton DK, Pilaz LJ, Singh Alvarado J, Calhan OY, Silver DL, Stevens B, Calakos N, Soderling SH, Eroglu C (2014) Astrocytes refine cortical connectivity at dendritic spines. Elife 3. CrossRef Medline

Sterio DC (1984) The unbiased estimation of number of sizes of arbitrary particles using the disector. J Microsc 134:127-136. CrossRef Medline

Taub E, Uswatte G, Elbert T (2002) New treatments in neurorehabilitation founded on basic research. Nat Rev Neurosci 3:228-236. CrossRef Medline

Tennant KA, Adkins DL, Donlan NA, Asay AL, Thomas N, Kleim JA, Jones TA (2011) The organization of the forelimb representation of the C57BL/6 mouse motor cortex as defined by intracortical microstimulation and cytoarchitecture. Cereb Cortex 21:865-876. CrossRef Medline

Ward NS, Cohen LG (2004) Mechanisms underlying recovery of motor function after stroke. Arch Neurol 61:1844-1848. CrossRef Medline

Witcher MR, Kirov SA, Harris KM (2007) Plasticity of perisynaptic astroglia during synaptogenesis in the mature rat hippocampus. Glia 55:13-23. CrossRef Medline

Xu T, Yu X, Perlik AJ, Tobin WF, Zweig JA, Tennant K, Jones T, Zuo Y (2009) Rapid formation and selective stabilization of synapses for enduring motor memories. Nature 462:915-919. CrossRef Medline 